\title{
Secukinumab for rheumatology: development and its potential place in therapy
}

This article was published in the following Dove Press journal:

Drug Design, Development and Therapy

24 June 2016

Number of times this article has been viewed

\section{Marije I Koenders \\ Wim B van den Berg}

Experimental Rheumatology, Radboud University Medical Center, Nijmegen, the Netherlands
Correspondence: Marije I Koenders Experimental Rheumatology, Radboud University Medical Center, PO Box 9101, 6500 HB Nijmegen, the Netherlands $\mathrm{Tel}+3 \mathrm{I} 243616619$

Fax +3I 243540403

Email marije.koenders@radboudumc.nl
Abstract: Rheumatic disease is not a single disorder, but a group of more than 100 diseases that affect joints, connective tissues, and/or internal organs. Although rheumatic diseases like rheumatoid arthritis (RA), psoriatic arthritis, and ankylosing spondylitis (AS) differ in their pathogenesis and clinical presentation, the treatment of these inflammatory disorders overlaps. Non-steroid anti-inflammatory drugs are used to reduce pain and inflammation. Additional disease-modifying anti-rheumatic drugs are prescribed to slowdown disease progression, and is in RA more frequently and effectively applied than in AS. Biologicals are a relatively new class of treatments that specifically target cytokines or cells of the immune system, like tumor necrosis factor alpha inhibitors or B-cell blockers. A new kid on the block is the interleukin-17 (IL-17) inhibitor secukinumab, which has been recently approved by the US Food and Drug Administration for moderate-to-severe plaque psoriasis, psoriatic arthritis, and AS. IL-17 is a proinflammatory cytokine that has an important role in host defense, but its proinflammatory and destructive effects have also been linked to pathogenic processes in autoimmune diseases like RA and psoriasis. Animal models have greatly contributed to further insights in the potential of IL-17 blockade in autoimmune and autoinflammatory diseases, and have resulted in the development of various potential drugs targeting the IL-17 pathway. Secukinumab (AIN457) is a fully human monoclonal antibody that selectively binds to IL-17A and recently entered the market under the brand name Cosenty ${ }^{\circledR}$. By binding to IL-17A, secukinumab prevents it from binding to its receptor and inhibits its ability to trigger inflammatory responses that play a role in the development of various autoimmune diseases. With secukinumab being the first in class to receive Food and Drug Administration approval, this article will further focus on this new biologic agent and review the milestones in its development and marketing.

Keywords: interlleukin-17, rheumatoid arthritis, psoriatic arthritis, ankylosing spondylitis

\section{Introduction}

Rheumatic diseases are characterized by pain and loss of function in one or more areas of the musculoskeletal system. It is not a single disorder, but a group of more than 100 diseases that affect joints; bones; cartilage; and connective tissues like tendons, ligaments, and muscles; they may also affect internal organs.

Arthritis (from Greek: arthro = joint, itis = inflammation) is one of the clinical manifestations of rheumatic diseases, and is characterized by pain, swelling, and stiffness of the affected synovial joints. Rheumatoid arthritis (RA) is the most common inflammation-driven rheumatic disease, which mainly affects the joints in a symmetrical manner and finally results in the destruction of cartilage and bone. This chronic autoimmune disease has been associated with genetic predisposition (eg, HLA-DR4, cytotoxic T-lymphocyte-associated antigen [CTLA]-4, and PTPN22) and environmental 
risk factors (eg, smoking and microorganisms), and is often accompanied by rheumatoid factor and anti-cyclic citrullinated protein antibodies as diagnostic and prognostic biomarkers for RA. ${ }^{1-3}$

In contrast to RA, psoriatic arthritis (PsA) and ankylosing spondylitis (AS) are considered seronegative rheumatic diseases; both PsA and AS are associated with genetic inheritance of the HLA-B27 gene. ${ }^{4,5}$ PsA is, like RA, also an inflammatory rheumatic disease characterized by arthritis and affects up to $30 \%$ of patients with the chronic skin condition psoriasis. ${ }^{6}$ Its peripheral joint involvement may range from mild asymmetric joint inflammation to severe erosive arthritis. AS, formerly also known as Bechterew's disease, is a rheumatic disease of the axial skeleton that mainly affects the spine and the sacroiliac joint in the pelvis. This spondyloarthropathy is characterized by erosion, sclerosis, and ossification, which may result in complete fusion and rigidity of the spine. ${ }^{7}$

Despite the differences in pathogenesis and clinical presentation of RA, PsA, and AS, the treatment of these inflammatory rheumatic disorders is very overlapping. Nonsteroidal anti-inflammatory drugs are used to reduce pain and inflammation in rheumatic diseases; also, additional disease-modifying antirheumatic drugs, such as methotrexate (MTX) and sulfasalazine, are prescribed to slow down disease progression, and are more frequently and effectively applied in RA than in AS. ${ }^{8}$ Biologicals form a relatively new class of treatments that specifically target specific cytokines or cells in the immune system. The most frequently applied biological agents approved for RA, PsA, and AS are tumor necrosis factor alpha (TNF $\alpha$ ) inhibitors (including infliximab, etanercept, adalimumab, golimumab, and certolizumab pegol). ${ }^{9}{ }^{10}$ For RA, alternative and approved biologicals are directed against CTLA-4-driven T-cells (abatacept), CD20expressing B-cells (rituximab), or the IL-6 receptor tocilizumab, and many new drugs are still in the pipeline. ${ }^{11-14}$

However, alternatives for anti-TNF treatment failed to show efficacy in $\mathrm{AS}^{15,16}$ or are still in clinical trial for AS and PsA. ${ }^{17-19}$ PsA patients may also experience relief of symptoms by using the IL-12/IL-23 inhibitor ustekinumab, or by treatment with the synthetic disease-modifying antirheumatic drug phosphodiesterase-4 inhibitor apremilast, which is also being tested in other rheumatic diseases like AS. ${ }^{20-22}$

A new kid on the block is the interleukin-17 (IL-17) inhibitor secukinumab, which has been recently approved by the US Food and Drug Administration (FDA) for moderateto-severe plaque psoriasis, PsA, and $\mathrm{AS}^{23,24}$ (Figure 1). Secukinumab (AIN457) is a fully human monoclonal antibody that selectively binds to IL-17A and is now registered by Novartis International AG under the brand name

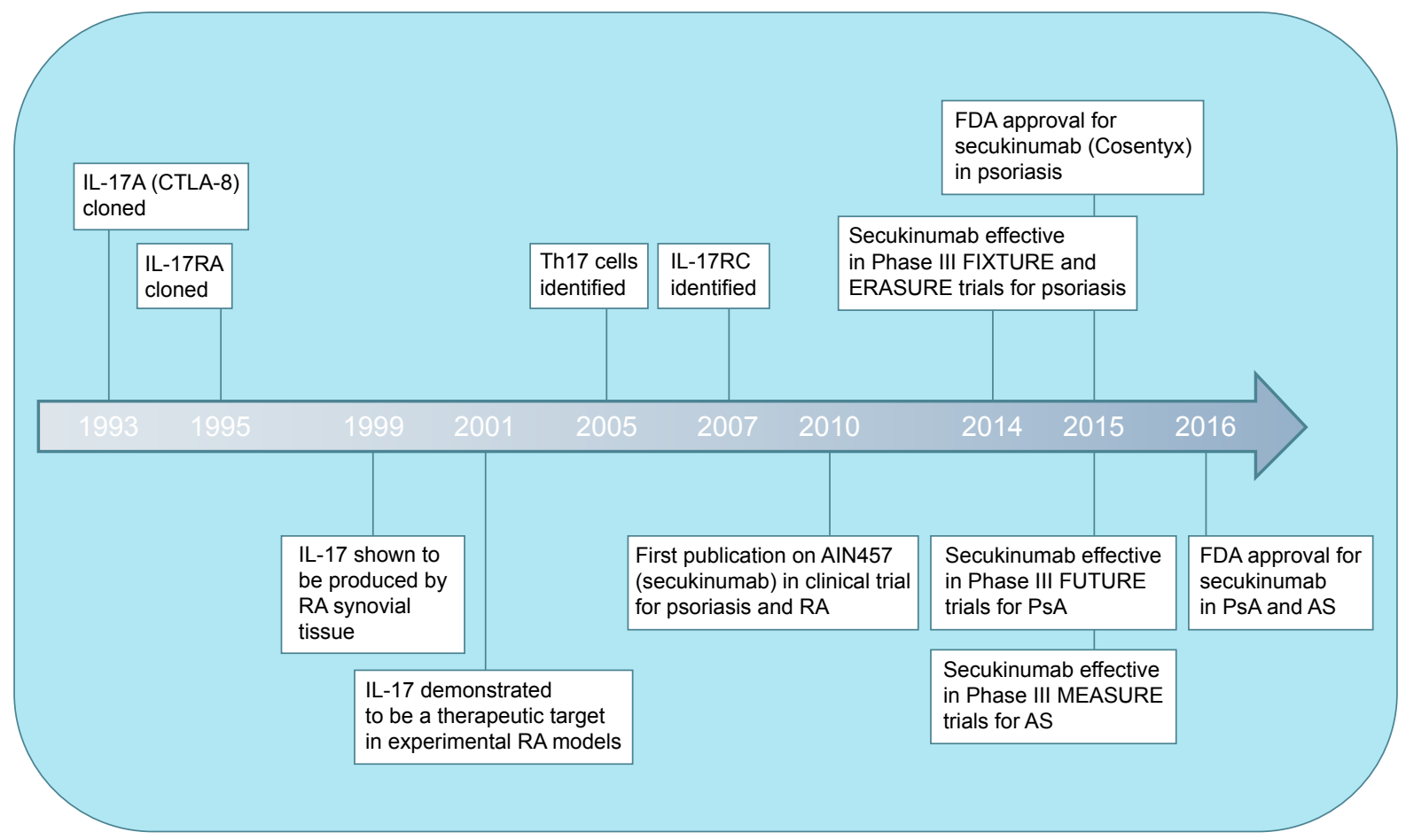

Figure I Milestones in the development of the therapeutic anti-IL-I7 antibody secukinumab.

Abbreviations: IL-17, interleukin I7; FDA, Food and Drug Administration; RA, rheumatoid arthritis; PsA, psoriatic arthritis; AS, ankylosing spondylitis; CTLA, cytotoxic T-lymphocyte-associated antigen; FIXTURE, Full Year Investigative Examination of Secukinumab vs Etanercept Using Two Dosing Regimens to Determine Efficacy in Psoriasis; ERASURE, Efficacy of Response and Safety of Two Fixed Secukinumab Regimens in Psoriasis. 
Cosenty $x^{\circledR}$. By binding to IL-17A, secukinumab prevents it from binding to its receptor and inhibits its ability to trigger inflammatory responses that play a role in the development of various autoimmune diseases.

\section{IL-I 7 and its biological function}

IL-17A is a proinflammatory cytokine that is a part of a family of six members (IL-17A to IL-17F). ${ }^{25}$ IL-17A, often referred to as IL-17, is a $17 \mathrm{kDa}$ protein that is secreted as a dimer and was first described as CTLA- 8 in the early nineties. ${ }^{26}$ IL-17 is mainly produced by a specific T-helper subset, the Th17 cell, ${ }^{27,28}$ although other immune cells like $\gamma \delta$ T-cells, natural killer cells, natural killer T-cells, innate lymphoid cells, neutrophils, and mast cells have also been described to express or produce this cytokine. ${ }^{29-31}$ Upon binding of IL-17 to its ubiquitously expressed receptor, IL-17RA pairs with IL-17RC to induce proinflammatory responses via TRAF6, $\mathrm{ACT} 1, \mathrm{NF}-\kappa \mathrm{B}, \mathrm{C} / \mathrm{EBP}$, and MAPKs. ${ }^{32,33}$

The existence of IL-17-producing $\mathrm{CD}^{+}{ }^{+} \mathrm{T}$-cells, Th17 cells, was only recently described after the discovery that the p40 subunit of IL-12 not only forms a heterodimer with IL-12p35, promoting interferon gamma-producing Th1 cells, but is also shared with IL-23p19. ${ }^{34,35}$ IL-23, together with tumor growth factor beta and IL-6, contributes to Th17 differentiation and survival under the control of transcription factor ROR $\gamma \mathrm{T} .^{36,37} \mathrm{Th} 17$ cells are abundant at mucosal interfaces like the gut, where IL-17 plays an important function in the protection against extracellular bacterial and fungal infections by upregulation of cytokines and antimicrobial peptides and by recruitment of neutrophils. ${ }^{38,39}$ In experimental studies, IL-17 was demonstrated to be required for host defense against Klebsiella pneumoniae infection in the lungs and Citrobacter rodentium infection in the gut. ${ }^{40}$ In patients suffering from the hyperimmunoglobulinemia $\mathrm{E}$ syndrome, an impaired IL-17 production by T-cells due to mutations in the Stat3 gene has been identified as the main cause of a devastating susceptibility for common pathogens like Staphylococcus aureus and Candida albicans, resulting in recurrent and often severe pulmonary infections, mucocutaneous candidiasis, eczema, and staphylococcal abscesses. ${ }^{41,42}$ These findings and the recently described effects of modulating the microbiome on T-cell biology underscore the importance of Th17 responses in mucosal homeostasis and immunity. ${ }^{43,44}$

\section{Target identification: IL- I 7 in rheumatic diseases}

Besides its role in immunity against infections, IL-17's proinflammatory and destructive effects have also been linked to pathogenic processes in autoimmune diseases like RA, psoriasis, and PsA. ${ }^{45}$ Stimulation of synovial fibroblasts with IL-17 induces the expression of IL-6, IL-8, and matrix metalloproteinases, ${ }^{46}$ thereby promoting inflammation and cartilage destruction. In addition, IL-17 in synovial fluids from RA patients has been shown to induce the expression of RANKL, ${ }^{47}$ an essential mediator for osteoclastogenesis and bone resorption. Interesting, IL-17 has been described to synergize with various proinflammatory cytokines, including TNF $\alpha,{ }^{48-51}$ implicating an important inflammatory and catabolic function for IL-17 in disease pathogenesis (Figure 2).

In RA patients, increased systemic and local levels of this proinflammatory cytokine can be found. RA synovial tissue was found to spontaneously produce IL-17, ${ }^{52}$ and elevated levels of this cytokine have been reported in the synovial fluid of RA patients. ${ }^{49}$ Also in blood, increased IL-17 expression has been observed in patients with RA; besides increased cytokine levels in serum, ${ }^{53,54}$ more IL-17 ${ }^{+}$ $\mathrm{CD}^{+}$Th17 cells were found in blood from RA patients compared to healthy controls. ${ }^{55}$ Recent studies reported that IL-17/Th17 levels were surprisingly increased by antiTNF treatment. ${ }^{56-58}$ Interestingly, in addition to $\mathrm{CD}^{+}$Th17 cells, $\mathrm{CD} 8^{+} \mathrm{IL}-17^{+}$cytotoxic T-cells have been described in the synovial fluid of PsA patients, and this Tc17 cell was shown to positively correlate with various markers of disease severity. ${ }^{59}$ In addition to the expression of IL-17, IL-17RC was also found to be upregulated in the synovial lining in PsA patients compared to osteoarthritis patients. ${ }^{60}$ For both PsA and AS, genome-wide association studies have identified polymorphisms of genes in the IL-17 pathway. PsA also has been associated with a polymorphism in the gene encoding for ACT1, a downstream signaling pathway of the IL-17 receptor. ${ }^{61}$ A single-nucleotide substitution in the $I L-23 R$ gene has been demonstrated to be protective against AS. ${ }^{62}$ Overall, IL-17 has been identified as a potential, interesting therapeutic target in RA, PsA, and AS, with further preclinical and clinical studies testing this hypothesis.

\section{Preclinical development of anti- IL- I 7 treatment}

Animal models have greatly contributed to further insights in the potential of IL-17 blockade in autoimmune and autoinflammatory diseases. Although animal models for PsA and AS are limited, many IL-17 inhibition studies have been performed in joint inflammation models resembling RA.

The complete absence of IL-17 in mice during collageninduced arthritis development markedly suppressed disease onset as well as arthritis severity, ${ }^{63}$ and the effect of IL-17 deficiency was even more pronounced in the spontaneous 

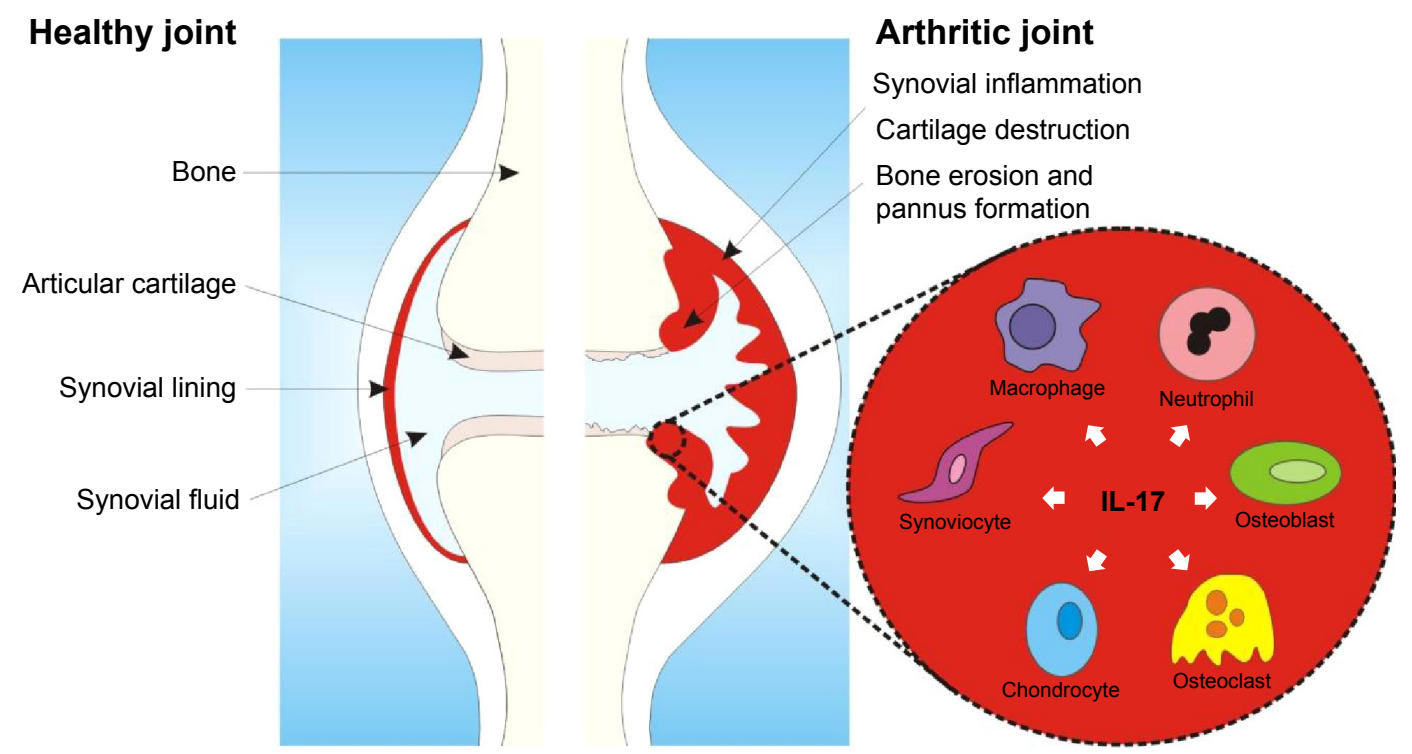

Figure 2 Simplified scheme of IL-17 and its effector cells in the inflamed arthritic joint.

Notes: In the inflamed arthritic joint, IL- I 7 activates resident cells like synovial fibroblasts and chondrocytes, and recruits proinflammatory immune cells thereby contributing to joint inflammation, cartilage destruction, and bone erosion.

Abbreviation: IL-17, interleukin 17.

arthritis development in mice deficient of the IL-1 receptor antagonist, where disease was completely prevented. ${ }^{64}$ Another approach, knocking out the IL-17RA subunit followed by chronic reactivated streptococcal cell wall-induced arthritis, demonstrated the requirement of IL-17R signaling for sustained and destructive joint inflammation. ${ }^{65}$

In contrast to complete absence of IL-17 signaling in transgenic mice, more refined inhibition of the IL-17 pathway in in vivo models has been applied using neutralizing antibodies directed against this cytokine, or with soluble IL-17 receptors fused to an immunoglobulin fragment crystallizable $(\mathrm{Fc})$-domain to increase its circulation time. Blocking of endogenous IL-17 in the autoimmune collagen-induced arthritis model significantly reduced arthritis progression without affecting antigen-specific $\mathrm{T}$ - and B-cell responses ${ }^{66}$ and was even effective in established disease in IL-1RAdeficient mice ${ }^{67}$ In reactivation of the murine antigen-induced arthritis model with local exposure to a small amount of methylated bovine serum albumin as antigen, flare of the joint inflammation and subsequent enhanced destruction could be completely prevented using anti-IL- 17 treatment. ${ }^{68}$ Interestingly, the additive or synergistic effects of IL-17 with other cytokines were proven in murine collagen-induced arthritis, where blocking of IL-17 in combination with TNF or granulocyte macrophage colony stimulating factor more effectively reduced joint pathology than either treatment alone. ${ }^{69-71}$

Although collagen-induced arthritis is considered one of the classical models for RA, the SKG mouse model may also present with features of spondyloarthritides, including AS and PsA. Upon systemic injection with beta-glucan, autoimmune-prone SKG mice with mutated ZAP-70 develop peripheral and axial arthritis, ileitis, and psoriasis-like skin inflammation. ${ }^{72}$ Reduced arthritis, spondylitis, and enthesitis in the absence of IL-17 or after treatment with IL-23 inhibitors ${ }^{73}$ also support the concept of IL-17 as a therapeutic target in these rheumatic diseases. This has finally led to the development of various IL-17 inhibitors: secukinumab and ixekizumab targeting IL-17 cytokines and brodalumab targeting IL-17RA. With secukinumab being the first in class to receive FDA approval, this article will further focus on this new biologic agent and review the milestones in its development and marketing (Figure 1).

\section{Safety profile of secukinumab}

The safety profile of secukinumab in various Phase II/III clinical trials on patients with rheumatic diseases was consistent with that observed with other biological therapies like etanercept. ${ }^{74}$ Most observed adverse events were mild to moderate in severity. Infections were more frequent with secukinumab than with placebo; nasopharyngitis or infections of the upper respiratory tract were most often reported. ${ }^{75-79}$ Some cases of mild-to-moderate candidiasis were reported, which resolved spontaneously or with oral therapy. ${ }^{77}$ Grade $2-3$ neutropenia was reported in a couple of patients, although this was not associated with increased risk of infection. ${ }^{80}$ The occurrence of reported serious adverse events could not be directly 
linked to secukinumab treatment, and no deaths occurred. ${ }^{74-80}$ Overall, after several Phase II and III clinical trials in psoriasis and various rheumatic diseases with no unexpected safety signals and no specific organ-related toxicities, secukinumab is in general considered safe and well tolerated.

One important safety issue, however, should be mentioned here that is not directly associated with secukinumab but with the IL-17R-inhibitor brodalumab, which showed significant clinical improvements in patients with moderate-to-severe psoriasis in the AMAGINE-2 and AMAGINE-3 trials. ${ }^{81}$ Mid 2015, Amgen Inc. unexpectedly announced that it was discontinuing its co-development of brodalumab with AstraZeneca plc based on events of suicidal ideation and behavior in the brodalumab program. ${ }^{82}$ AstraZeneca plc claimed the observations of suicidal ideation and behavior are unlikely to be causally related to brodalumab therapy and is continuing full analysis of the AMAGINE studies. Without the exact details of these deaths in relation to their treatment, speculation on other confounding factors like a national surge in suicidality during the recent economic crisis, ${ }^{83}$ particularly affecting the study population in these trials, will not save the bad reputation of this IL-17R inhibitor. Despite all these, in January 2016 , a Biologics License Application was submitted to the FDA by AstraZeneca plc in partnership with Valeant Pharmaceuticals, and a response is due by the end of the year.

Although secukinumab is far ahead of brodalumab in its clinical marketing and development, and suicidality is not a reported issue during its clinical trials, the concerns raised by the brodalumab program may influence ongoing secukinumab programs and may put mental health of future secukinumab users under the microscope.

\section{Therapeutic value of secukinumab in psoriasis}

Before discussing the therapeutic value of secukinumab in rheumatic diseases, the impressive results of this anti-IL-17 antibody in the treatment of plaque psoriasis need to be mentioned here. Plaque psoriasis is a chronic inflammatory skin disease characterized by raised areas of inflamed skin covered with silvery-white scaly skin. After the first-in-man study with secukinumab already demonstrating highly significant effects on psoriasis severity, ${ }^{84}$ a Phase II, randomized, doubleblind, placebo-controlled trial was performed on 125 patients with moderate-to-severe plaque psoriasis. ${ }^{85}$ Subcutaneous injections with secukinumab at 4-week intervals resulted in significantly higher PASI75 scores, indicating at least 75\% improvement from baseline in the Psoriasis Area and Severity Index score: $82 \%$ in the $150 \mathrm{mg}$ arm $(P<0.001)$ and $57 \%$ in the $75 \mathrm{mg}$ arm $(P=0.002)$ versus $9 \%$ in the placebo group (Papp, BRD2013). ${ }^{85}$ This study was followed by several Phase III trials, which further confirmed and proved the clinical efficacy of this anti-IL-17 antibody in psoriasis. The ERASURE, FIXTURE, and FEATURE trials achieved their primary efficacy endpoint of PASI75 at week 12 with over $75 \%$ of the patients on $300 \mathrm{mg}$ reaching PASI75 compared to $<5 \%$ in the placebo controls (3REF), ${ }^{74,86}$ resulting in rapid FDA approval for secukinumab for its first indication: moderate-to-severe plaque psoriasis ${ }^{23}$ (Figure 1). Key trials with secukinumab in psoriasis and rheumatic diseases are summarized in Table 1, providing a quick overview of the study design and primary endpoints in various Phase II/III clinical trials.

\section{Therapeutic value of secukinumab in RA \\ Phase I}

In 2010, the combined results of three clinical trials on the safety and possible efficacy of secukinumab in RA, psoriasis, and chronic noninfectious uveitis were published. ${ }^{84}$ In the RA trial, 52 patients were enrolled (26 AIN457- and 26 placebo-treated patients) for a 16-week study with two infusions of AIN457 $(10 \mathrm{mg} / \mathrm{kg})$ at an interval of 3 weeks. Although the primary efficacy endpoint was not achieved, this study provided the first indications of clinical responses to secukinumab. The American College of Rheumatology 20\% response (ACR20) rate expressed as area under the responsetime curve was significantly higher in the secukinumab group than in the placebo control group, and this was also found for the 28-joint disease activity score (DAS28) and the serological inflammation marker C-reactive protein (CRP) ${ }^{84}$

\section{Phase II}

In contrast to the impressive effects of anti-IL-17 treatment in psoriasis, published Phase II/III randomized controlled trials failed to demonstrate convincing data that secukinumab is effective in RA. The efficacy and safety of secukinumab were investigated in a double-blind, randomized, placebocontrolled Phase II study including 237 RA patients with inadequate response to MTX, who were randomly assigned to monthly subcutaneous injections of $25,75,150$, or $300 \mathrm{mg}$ secukinumab or placebo. ${ }^{75}$ At week 16, this resulted in ACR20 responses of $34.0 \%, 46.9 \%, 46.5 \%$, and $53.7 \%$, respectively, for the doses of secukinumab, compared to $36.0 \%$ in the placebo arm. However, these differences did not reach statistical significance, thereby failing to show clinical efficacy for secukinumab in RA. Although this primary 


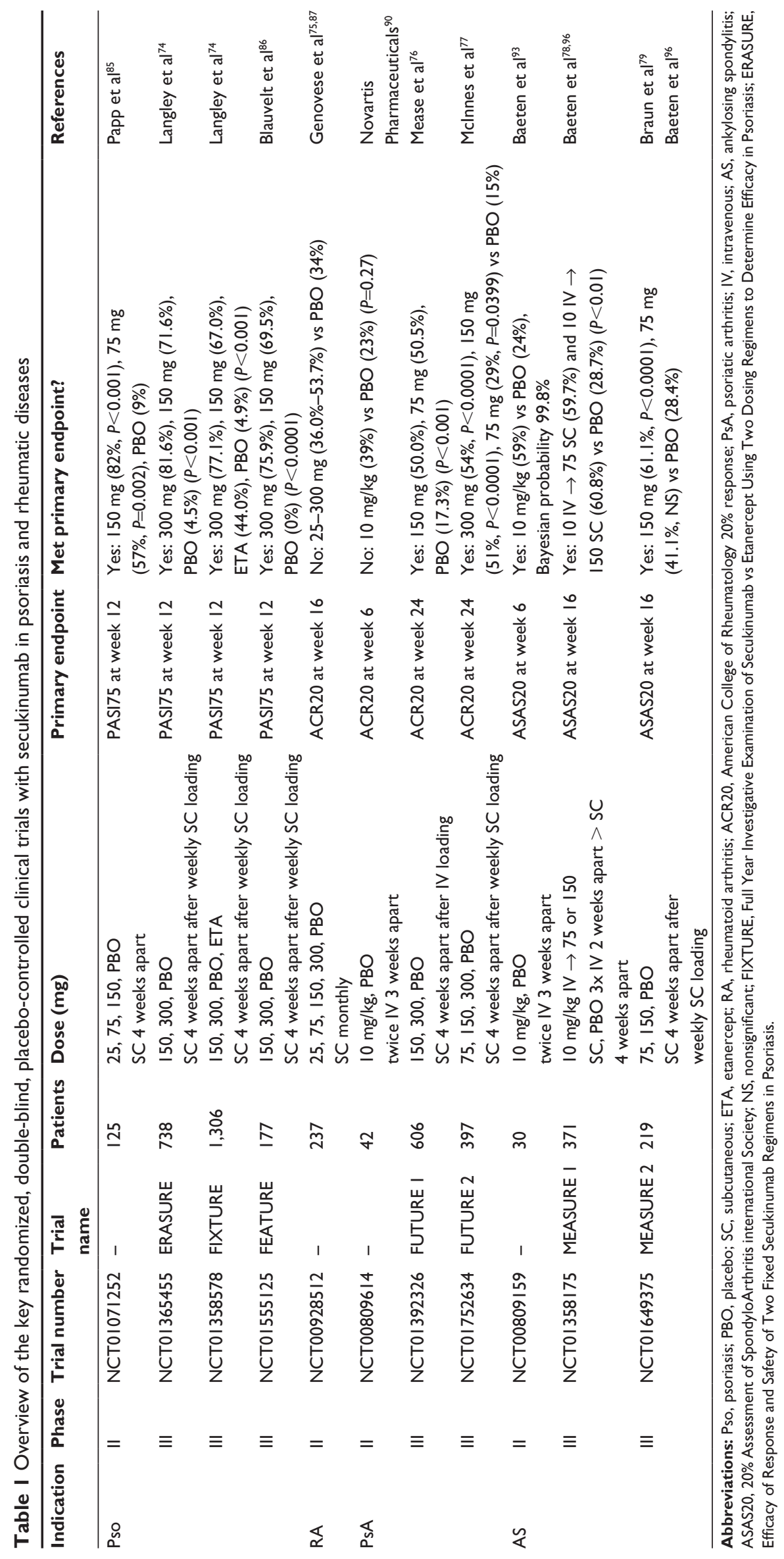


efficacy endpoint of significant ACR20 responses at 16 weeks was not achieved, beneficial effects of the secukinumab doses 75,150 , and $300 \mathrm{mg}$ were observed on DAS28-CRP scores. ${ }^{75}$ When evaluating the long-term safety and efficacy in a follow-up study till 52 weeks, RA patients responding to secukinumab in the first 16 weeks showed a sustained clinical response, or even further improvement in their response rates up to week 52. ${ }^{87} \mathrm{~A}$ recent Phase II biomarker study investigating the association of HLA-DRB1 alleles with clinical response to secukinumab was actually the first and only study to demonstrate the clinical efficacy of secukinumab over a placebo arm in RA with significantly better ACR20 response rates $(87.1 \%$ in the secukinumab group vs $25.0 \%$ in the placebo group) and reduced DAS28-CRP at week $12,{ }^{80}$ although no association was found between the HLA-DRB1*04 allele and response to secukinumab treatment. Current data from a limited set of Phase II trials are not convincing, and evidence for the efficacy of secukinumab in RA from a proper Phase III trial is still lacking. Preclinical research using the human RA synovium SCID mouse model demonstrated that anti-IL-17 was only effective when the synovial tissue was rich in $\mathrm{CD}^{+} \mathrm{T}$-cells, ${ }^{88}$ suggesting that determining the $\mathrm{T}$-cell dominance in RA patients using a set of biomarkers might help to predict the responsiveness to secukinumab treatment.

\section{Phase III}

Various Phase III studies on secukinumab in RA have recently been completed (eg, NCT01350804 and NCT01640938) or are still in progress (NCT01901900 and NCT01770379). ${ }^{89,90}$ More information will be obtained in the next few years on the clinical efficacy of this anti-IL-17 inhibitor in RA patients on MTX or with an inadequate response to anti-TNF agents. These results will yield a final verdict on the efficacy of secukinumab in RA and will further define the potential clinical utility of this treatment in patients with RA.

\section{Application of secukinumab in PsA}

Compared to RA, clinical trials on secukinumab for the treatment of PsA are much further in progress, and Novartis International AG filed a regulatory application for secukinumab as a PsA drug in the US and EU in Q2 2015. A Phase II proof-of-concept trial in 42 patients with active PsA did not meet its primary endpoint of ACR20 response at week 6, with ACR20 response in 39\% of patients for secukinumab versus $23 \%$ for placebo $(P=0.27)$, although significant improvement in the acute-phase proteins CRP and erythrocyte sedimentation rate (ESR) and quality of life as secondary endpoints suggested some clinical benefit from secukinumab treatment in PsA. ${ }^{91}$ Recent results from the randomized, placebo-controlled Phase III FUTURE 1 and 2 trials (NCT01392326 and NCT01752634) indicate that secukinumab is indeed an efficacious treatment for patients with PsA. ${ }^{76,77}$ FUTURE 1 included 606 PsA patients randomly assigned to intravenous secukinumab followed by subcutaneous treatment with this IL-17 blocker at two different doses (150 or $300 \mathrm{mg}$ ), or placebo, and resulted in impressive and significant improvement in ACR20 and the American College of Rheumatology 50\% response (ACR50), as well as two psoriasis area and severity indexes (PASI75 and PASI90) as secondary outcome parameters. ${ }^{76}$ FUTURE 2 had a slightly different design with 397 PsA patients receiving subcutaneous injections of either placebo or secukinumab 75,150 , or $300 \mathrm{mg}$ once a week for 4 weeks, continued every 4 weeks. ${ }^{77}$ Also in this Phase III trial, the primary efficacy endpoint was met for all the secukinumab doses, as secukinumab treatment clearly improved the signs and symptoms of PsA; with secukinumab $300 \mathrm{mg}$, 54\% of the patients achieved ACR20 at week 24 versus 51\% with $150 \mathrm{mg}, 29 \%$ with $75 \mathrm{mg}$, and $15 \%$ with placebo. ${ }^{77}$ In line with this impressive effect on the primary endpoint, for the doses 75 and $150 \mathrm{mg}$, significant effects were reported on various secondary endpoints, including PASI75 and PASI90, DAS28-CRP, and ACR50. Interestingly, clinical response rates were generally higher in anti-TNF-naive patients than in anti-TNF inadequate responders, with the low-dose (75 mg) secukinumab group failing to show significant ACR20 and ACR50 responses to secukinumab treatment upon stratification. ${ }^{77}$ Overall, these FUTURE trials have build an impressive record on the efficacy of secukinumab in PsA, resulting in the European and US FDA approval for secukinumab for PsA, together with the approval for AS, in November 2015 and January 2016, respectively. ${ }^{24,92}$

\section{Treatment of AS}

As already mentioned, the European Medicines Agency and FDA have approved secukinumab for the treatment of AS since multiple clinical trials have demonstrated its positive findings in AS. To test the safety and efficacy of secukinumab in AS, a randomized, double-blind, placebocontrolled Phase II trial was performed among 30 patients with moderate-to-severe AS. ${ }^{93}$ Secukinumab administered intravenously 3 weeks apart was well tolerated and clinically efficacious, as convincingly demonstrated by improved $20 \%$ Assessment of SpondyloArthritis international Society response rates at week 6 (59.2\% with secukinumab vs $24.5 \%$ 
with placebo), with Bayesian analysis indicating a probability of $99.8 \%$ of secukinumab inducing greater response rates than placebo. ${ }^{93}$ A follow-up study demonstrated a sustained clinical response in the majority of these AS patients when secukinumab was continued at $3 \mathrm{mg} / \mathrm{kg}$ every 4 weeks until week 94, which was accompanied by regression of inflammatory spinal lesions as assessed by magnetic resonance imaging. ${ }^{94}$ Recent results of the Phase III MEASURE 1 and 2 trials (NCT01358175 and NCT01649375) presented at the ACR conferences in Boston (2014) ${ }^{78}$ and San Francisco $(2015)^{79,95}$ and published by Baeten et $\mathrm{al}^{96}$ confirmed that secukinumab resulted in rapid and significant improvement of signs and symptoms in patients with active AS, ${ }^{78,79}$ with $\sim 61 \%$ of the patients in the $150 \mathrm{mg}$ secukinumab arms showing 20\% Assessment of SpondyloArthritis international Society response at week 16 compared to $28 \%$ in the placebo arms. Data from both the MEASURE trials also indicated that secukinumab was associated with a reduction of spinal inflammation as assessed by magnetic resonance imaging, as in $\sim 80 \%$ of the patients treated with secukinumab for 104 weeks no radiographic progression was observed..$^{95}$ Other Phase III trials are ongoing to provide even more evidence on long-term safety and efficacy of secukinumab in AS (NTC02008916, NCT01863732, and NCT02159053), with results expected in 2017/2018.

\section{Other rheumatic diseases: Behçet's disease}

A 24-week, randomized, double-blinded, placebo-controlled Phase III trial was conducted in 118 Behçet's patients with posterior uveitis or panuveitis to assess the difference in the rate of recurrent exacerbations when treated with secukinumab versus placebo adjunctive to standard-of-care immunosuppressive therapy. This trial (NCT00995709) failed to demonstrate clinical improvement and showed a similar rate of recurrent ocular exacerbations during 24 weeks of treatment. Additional trials investigating the efficacy of secukinumab in (Behçet's) uveitis were halted (eg, NCT01093846, NCT01032915, NCT01090310, and NCT01103024) or withdrawn (NCT01327664).

\section{Secukinumab in Crohn's disease}

Expectations were high when anti-IL-17 treatment was recently tested in Crohn's disease (CD), but it results in dramatic failure of both secukinumab as well as AMG 827 for this indication. ${ }^{97,98}$ The multicenter Phase II trial on secukinumab in 59 patients with established moderate-to-severe CD was prematurely terminated. Secukinumab did not help in improving CD; moreover, worsening of the disease was reported as reflected in the high rate of serious adverse events as well as fungal infections. ${ }^{97}$ It seems that the role of IL-17 in diseases like CD has to be revisited, as more and more studies have uncovered the protective effects of IL-17 at mucosal sides, important for host defense and immune homeostasis together with other Th17 cytokines like IL-22.99

\section{Secukinumab in autoinflammatory syndromes}

In contrast to autoimmune diseases with a dysregulated adaptive immune system, autoinflammatory syndromes like familial Mediterranean fever and TNF receptor-associated periodic syndrome are caused by an exaggerated innate immune system response resulting in episodes of spontaneous inflammation affecting multiple organs. This major difference in pathogenesis also affects the type of treatments applied; rather than anti-TNF, CTLA-4-Ig, or B-cell-based biologicals, corticosteroids or anti-IL-1 treatment are most frequently applied. Many autoinflammatory diseases are linked to a dysfunctional caspase-1 activity and increased secretion of IL-1 $\beta$ by monocytes/macrophages, and the blocking of IL-1 $\beta$ has resulted in dramatic improvement in various autoinflammatory diseases. ${ }^{100}$ As the role of T-cells like Th17 cells in the pathogenesis of this type of inflammations is minimal or absent, the potential of secukinumab treatment in autoinflammatory disease will be only based on IL-17 production by innate immune cells and is therefore expected to be very limited.

\section{Conclusion: potential place in therapy}

After demonstrating great clinical efficacy in psoriasis ${ }^{74}$ secukinumab received its first global approval in Japan on Boxing Day 2014 for the treatment of psoriasis and PsA. The secukinumab US regulatory application for moderate-tosevere plaque psoriasis was filed in October 2013, with subsequent FDA recommendation in October 2014 and final FDA approval granted on January 21, 2015. Regulatory approval for secukinumab for the indications of AS and PsA was recently obtained in Europe and the US at the end of 2015/ in early 2016. ${ }^{24,92}$ Depending on the outcome of Phase III trials on secukinumab in RA, this may be followed by filing for RA in the coming years, although it must be stressed that convincing clinical efficacy data for secukinumab in RA are still lacking and most likely will not show similar efficacy as demonstrated in other rheumatic diseases such as PsA and AS. With secukinumab entering the market, international 
treatment guidelines for various rheumatic diseases ${ }^{101-104}$ may need to be updated, giving this IL-17 inhibitor as first in a novel class of drugs a position and ranking between the current available treatments for patients with various inflammatory rheumatic diseases.

\section{Acknowledgment}

This work was sponsored by the Innovative Medicines Initiative Joint Undertaking funded project BTCure (grant number: agreement 115142-2).

\section{Disclosure}

The authors report no conflicts of interest in this work.

\section{References}

1. Scott DL, Wolfe F, Huizinga TW. Rheumatoid arthritis. Lancet. 2010; 376(9746):1094-1108.

2. McInnes IB, Schett G. The pathogenesis of rheumatoid arthritis. NEngl J Med. 2011;365(23):2205-2219.

3. Klareskog L, Amara K, Malmström V. Adaptive immunity in rheumatoid arthritis: anticitrulline and other antibodies in the pathogenesis of rheumatoid arthritis. Curr Opin Rheumatol. 2014;26(1):72-79.

4. Eder L, Chandran V, Pellet F, et al. Human leucocyte antigen risk alleles for psoriatic arthritis among patients with psoriasis. Ann Rheum Dis. 2012; 71(1):50-55.

5. Brown MA, Kenna T, Wordsworth BP. Genetics of ankylosing spondylitis-insights into pathogenesis. Nat Rev Rheumatol. 2016;12(2):81-91

6. Kane D, Stafford L, Bresnihan B, FitzGerald O. A prospective, clinical and radiological study of early psoriatic arthritis: an early synovitis clinic experience. Rheumatology (Oxford). 2003;42(12):1460-1468.

7. van der Heijde D, Bellamy N, Calin A, Dougados M, Khan MA, van der Linden S. Preliminary core sets for endpoints in ankylosing spondylitis. Assessments in Ankylosing Spondylitis Working Group. J Rheumatol. 1997;24(11):2225-2229.

8. Colebatch AN, Marks JL, Edwards CJ. Safety of non-steroidal antiinflammatory drugs, including aspirin and paracetamol (acetaminophen) in people receiving methotrexate for inflammatory arthritis (rheumatoid arthritis, ankylosing spondylitis, psoriatic arthritis, other spondyloarthritis). Cochrane Database Syst Rev. 2011;(11):CD008872.

9. van der Heijde D, Breban M, Halter D, et al. Maintenance of improvement in spinal mobility, physical function and quality of life in patients with ankylosing spondylitis after 5 years in a clinical trial of adalimumab. Rheumatology (Oxford). 2015;54(7):1210-1219.

10. Scirè $\mathrm{CA}$, Caporali R, Sarzi-Puttini $\mathrm{P}$, et al; Monitornet project. Drug survival of the first course of anti-TNF agents in patients with rheumatoid arthritis and seronegative spondyloarthritis: analysis from the MonitorNet database. Clin Exp Rheumatol. 2013;31(6) 857-863.

11. O'Dell JR, Mikuls TR, Taylor TH, et al; CSP 551 RACAT Investigators. Therapies for active rheumatoid arthritis after methotrexate failure. N Engl J Med. 2013;369(4):307-318.

12. Smolen JS, Landewé R, Breedveld FC, et al. EULAR recommendations for the management of rheumatoid arthritis with synthetic and biological disease-modifying antirheumatic drugs: 2013 update. Ann Rheum Dis. 2014;73(3):492-509.

13. Nam JL, Ramiro S, Gaujoux-Viala C, et al. Efficacy of biological diseasemodifying antirheumatic drugs: a systematic literature review informing the 2013 update of the EULAR recommendations for the management of rheumatoid arthritis. Ann Rheum Dis. 2014;73(3):516-528.

14. Koenders MI, van den Berg WB. Novel therapeutic targets in rheumatoid arthritis. Trends Pharmacol Sci. 2015;36(4):189-195.
15. Sieper J, Porter-Brown B, Thompson L, Harari O, Dougados M. Assessment of short-term symptomatic efficacy of tocilizumab in ankylosing spondylitis: results of randomised, placebo-controlled trials. Ann Rheum Dis. 2014;73(1):95-100.

16. Song IH, Heldmann F, Rudwaleit M, et al. Treatment of active ankylosing spondylitis with abatacept: an open-label, 24-week pilot study. Ann Rheum Dis. 2011;70(6):1108-1110.

17. Song IH, Heldmann F, Rudwaleit M, et al. One-year follow-up of ankylosing spondylitis patients responding to rituximab treatment and re-treated in case of a flare. Ann Rheum Dis. 2013;72(2):305-306.

18. Jimenez-Boj E, Stamm TA, Sadlonova M, et al. Rituximab in psoriatic arthritis: an exploratory evaluation. Ann Rheum Dis. 2012;71(11): $1868-1871$.

19. Mease P, Genovese MC, Gladstein G, et al. Abatacept in the treatment of patients with psoriatic arthritis: results of a six-month, multicenter, randomized, double-blind, placebo-controlled, phase II trial. Arthritis Rheum. 2011;63(4):939-948.

20. McInnes IB, Kavanaugh A, Gottlieb AB, et al; PSUMMIT 1 Study Group. Efficacy and safety of ustekinumab in patients with active psoriatic arthritis: 1 year results of the phase 3, multicentre, doubleblind, placebo-controlled PSUMMIT 1 trial. Lancet. 2013;382(9894): 780-789.

21. Gossec L, Smolen JS, Ramiro S, et al. European League Against Rheumatism (EULAR) recommendations for the management of psoriatic arthritis with pharmacological therapies: 2015 update. Ann Rheum Dis. 2016;75(3):499-510.

22. Celgene Corporation. Study of Apremilast to Treat Subjects With Active Ankylosing Spondylitis (POSTURE). Available from: https:// clinicaltrials.gov/ct2/show/NCT01583374

23. U.S. Food and Drug Administration. FDA approves new psoriasis drug Cosentyx. Available from: http://www.fda.gov/NewsEvents/Newsroom/ PressAnnouncements/ucm430969.htm

24. Novartis. Novartis receives two new FDA approvals for Cosentyx to treat patients with ankylosing spondylitis and psoriatic arthritis in the US. Available from: https://www.novartis.com/news/media-releases/ novartis-receives-two-new-fda-approvals-cosentyx-treat-patientsankylosing

25. Aggarwal S, Gurney AL. IL-17: prototype member of an emerging cytokine family. J Leukoc Biol. 2002;71(1):1-8.

26. Rouvier E, Luciani MF, Mattéi MG, Denizot F, Golstein P. CTLA-8, cloned from an activated $\mathrm{T}$ cell, bearing AU-rich messenger RNA instability sequences, and homologous to a herpesvirus saimiri gene. J Immunol. 1993;150(12):5445-5456.

27. Harrington LE, Hatton RD, Mangan PR, et al. Interleukin 17-producing CD4+ effector T cells develop via a lineage distinct from the $\mathrm{T}$ helper type 1 and 2 lineages. Nat Immunol. 2005;6(11):1123-1132.

28. Park H, Li Z, Yang XO, et al. A distinct lineage of CD4 T cells regulates tissue inflammation by producing interleukin 17. Nat Immunol. 2005; 6(11):1133-1141.

29. Gladiator A, WanglerN, Trautwein-Weidner K, LeibundGut-Landmann S. Cutting edge: IL-17-secreting innate lymphoid cells are essential for host defense against fungal infection. J Immunol. 2013;190(2): 521-525.

30. Ferretti S, Bonneau O, Dubois GR, Jones CE, Trifilieff A. IL-17, produced by lymphocytes and neutrophils, is necessary for lipopolysaccharide-induced airway neutrophilia: IL-15 as a possible trigger. J Immunol. 2003;170(4):2106-2112.

31. Buckland J. New role for mast cells as IL-17-expressing effector cells in established RA. Nat Rev Rheumatol. 2010;6(5):243.

32. Schwandner R, Yamaguchi K, Cao Z. Requirement of tumor necrosis factor receptor-associated factor (TRAF) 6 in interleukin 17 signal transduction. J Exp Med. 2000;191(7):1233-1240.

33. Gaffen SL. Structure and signalling in the IL-17 receptor family. Nat Rev Immunol. 2009;9(8):556-567.

34. Murphy CA, Langrish CL, Chen Y, et al. Divergent pro- and antiinflammatory roles for IL-23 and IL-12 in joint autoimmune inflammation. J Exp Med. 2003;198(12):1951-1957. 
35. Cua DJ, Sherlock J, Chen Y, et al. Interleukin-23 rather than interleukin-12 is the critical cytokine for autoimmune inflammation of the brain. Nature. 2003;421(6924):744-748.

36. Ivanov II, McKenzie BS, Zhou L, et al. The orphan nuclear receptor RORgammat directs the differentiation program of proinflammatory IL-17+ T helper cells. Cell. 2006;126(6):1121-1133.

37. Manel N, Unutmaz D, Littman DR. The differentiation of human $\mathrm{T}(\mathrm{H})-17$ cells requires transforming growth factor-beta and induction of the nuclear receptor RORgammat. Nat Immunol. 2008;9(6): 641-649.

38. Ye P, Rodriguez FH, Kanaly S, et al. Requirement of interleukin 17 receptor signaling for lung $\mathrm{CXC}$ chemokine and granulocyte colonystimulating factor expression, neutrophil recruitment, and host defense. J Exp Med. 2001;194(4):519-527.

39. Huang W, Na L, Fidel PL, Schwarzenberger P. Requirement of interleukin-17A for systemic anti-Candida albicans host defense in mice. J Infect Dis. 2004;190(3):624-631.

40. Ouyang W, Kolls JK, Zheng Y. The biological functions of T helper 17 cell effector cytokines in inflammation. Immunity. 2008;28(4): 454-467.

41. Milner JD, Brenchley JM, Laurence A, et al. Impaired T(H)17 cell differentiation in subjects with autosomal dominant hyper-IgE syndrome. Nature. 2008;452(7188):773-776.

42. Ma CS, Chew GY, Simpson N, et al. Deficiency of Th17 cells in hyper IgE syndrome due to mutations in STAT3. J Exp Med. 2008; 205(7):1551-1557.

43. Burkett PR, Meyer zu Horste G, Kuchroo VK. Pouring fuel on the fire: Th17 cells, the environment, and autoimmunity. J Clin Invest. 2015; 125(6):2211-2219.

44. Wu HJ, Ivanov II, Darce J, et al. Gut-residing segmented filamentous bacteria drive autoimmune arthritis via T helper 17 cells. Immunity. 2010; 32(6):815-827.

45. Kirkham BW, Kavanaugh A, Reich K. Interleukin-17A: a unique pathway in immune-mediated diseases: psoriasis, psoriatic arthritis and rheumatoid arthritis. Immunology. 2014;141(2):133-142.

46. Fossiez F, Djossou O, Chomarat P, et al. T cell interleukin-17 induces stromal cells to produce proinflammatory and hematopoietic cytokines. $J$ Exp Med. 1996;183(6):2593-2603.

47. Kotake S, Udagawa N, Takahashi N, et al. IL-17 in synovial fluids from patients with rheumatoid arthritis is a potent stimulator of osteoclastogenesis. J Clin Invest. 1999;103(9):1345-1352.

48. Chabaud M, Miossec P. The combination of tumor necrosis factor alpha blockade with interleukin-1 and interleukin-17 blockade is more effective for controlling synovial inflammation and bone resorption in an ex vivo model. Arthritis Rheum. 2001;44(6):1293-1303.

49. LeGrand A, Fermor B, Fink C, et al. Interleukin-1, tumor necrosis factor alpha, and interleukin-17 synergistically up-regulate nitric oxide and prostaglandin E2 production in explants of human osteoarthritic knee menisci. Arthritis Rheum. 2001;44(9):2078-2083.

50. Koshy PJ, Henderson N, Logan C, Life PF, Cawston TE, Rowan AD. Interleukin 17 induces cartilage collagen breakdown: novel synergistic effects in combination with proinflammatory cytokines. Ann Rheum Dis. 2002;61(8):704-713.

51. Van Bezooijen RL, Van Der Wee-Pals L, Papapoulos SE, Löwik CW. Interleukin 17 synergises with tumour necrosis factor alpha to induce cartilage destruction in vitro. Ann Rheum Dis. 2002;61(10): 870-876.

52. Chabaud M, Durand JM, Buchs N, et al. Human interleukin-17: A T cell-derived proinflammatory cytokine produced by the rheumatoid synovium. Arthritis Rheum. 1999;42(5):963-970.

53. Ziolkowska M, Koc A, Luszczykiewicz G, et al. High levels of IL-17 in rheumatoid arthritis patients: IL-15 triggers in vitro IL-17 production via cyclosporin A-sensitive mechanism. J Immunol. 2000;164(5): 2832-2838.

54. Gullick NJ, Abozaid HS, Jayaraj DM, et al. Enhanced and persistent levels of interleukin (IL)-17 ${ }^{+} \mathrm{CD} 4^{+} \mathrm{T}$ cells and serum IL-17 in patients with early inflammatory arthritis. Clin Exp Immunol. 2013;174(2): 292-301.
55. Shen H, Xia L, Lu J, Xiao W. Infliximab reduces the frequency of interleukin 17-producing cells and the amounts of interleukin 17 in patients with rheumatoid arthritis. J Investig Med. 2010;58(7):905-908.

56. Chen DY, Chen YM, Chen HH, Hsieh CW, Lin CC, Lan JL. Increasing levels of circulating Th17 cells and interleukin-17 in rheumatoid arthritis patients with an inadequate response to anti-TNF- $\alpha$ therapy. Arthritis Res Ther. 2011;13(4):R126.

57. Alzabin S, Abraham SM, Taher TE, et al. Incomplete response of inflammatory arthritis to TNF $\alpha$ blockade is associated with the Th17 pathway. Ann Rheum Dis. 2012;71(10):1741-1748.

58. Hull DN, Williams RO, Pathan E, Alzabin S, Abraham S, Taylor PC. Anti-tumour necrosis factor treatment increases circulating $\mathrm{T}$ helper type 17 cells similarly in different types of inflammatory arthritis. Clin Exp Immunol. 2015;181(3):401-406.

59. Menon B, Gullick NJ, Walter GJ, et al. Interleukin-17+ CD8+ T cells are enriched in the joints of patients with psoriatic arthritis and correlate with disease activity and joint damage progression. Arthritis Rheumatol. 2014;66(5):1272-1281.

60. Van Baarsen LGM, Lebre MC, van der Coelen D, Snoek BC, Gerlag DM, Tak PP. IL-17 levels in synovium of patients with rheumatoid arthritis, psoriatic arthritis and osteoarthritis: target validation in various forms of arthritis. Ann Rheum Dis. 2011;70:A79.

61. Hüffmeier U, Uebe S, Ekici AB, et al. Common variants at TRAF3IP2 are associated with susceptibility to psoriatic arthritis and psoriasis. Nat Genet. 2010;42(11):996-999.

62. Rueda B, Orozco G, Raya E, et al. The IL23R Arg381Gln nonsynonymous polymorphism confers susceptibility to ankylosing spondylitis. Ann Rheum Dis. 2008;67(10):1451-1454.

63. Nakae S, Nambu A, Sudo K, Iwakura Y. Suppression of immune induction of collagen-induced arthritis in IL-17-deficient mice. J Immunol. 2003;171(11):6173-6177

64. Nakae S, Saijo S, Horai R, Sudo K, Mori S, Iwakura Y. IL-17 production from activated $\mathrm{T}$ cells is required for the spontaneous development of destructive arthritis in mice deficient in IL-1 receptor antagonist. Proc Natl Acad Sci U S A. 2003;100(10):5986-5990.

65. Koenders MI, Kolls JK, Oppers-Walgreen B, et al. Interleukin-17 receptor deficiency results in impaired synovial expression of interleukin-1 and matrix metalloproteinases 3, 9, and 13 and prevents cartilage destruction during chronic reactivated streptococcal cell wall-induced arthritis. Arthritis Rheum. 2005;52(10):3239-3247.

66. Lubberts E, Koenders MI, Oppers-Walgreen B, et al. Treatment with a neutralizing anti-murine interleukin-17 antibody after the onset of collagen-induced arthritis reduces joint inflammation, cartilage destruction, and bone erosion. Arthritis Rheum. 2004;50(2):650-659.

67. Koenders MI, Devesa I, Marijnissen RJ, et al. Interleukin-1 drives pathogenic Th17 cells during spontaneous arthritis in interleukin-1 receptor antagonist-deficient mice. Arthritis Rheum. 2008;58(11): 3461-3470.

68. Koenders MI, Lubberts E, Oppers-Walgreen B, et al. Blocking of interleukin-17 during reactivation of experimental arthritis prevents joint inflammation and bone erosion by decreasing RANKL and interleukin-1. Am J Pathol. 2005;167(1):141-149.

69. Koenders MI, Marijnissen RJ, Devesa I, et al. Tumor necrosis factorinterleukin-17 interplay induces S100A8, interleukin-1 $\beta$, and matrix metalloproteinases, and drives irreversible cartilage destruction in murine arthritis: rationale for combination treatment during arthritis. Arthritis Rheum. 2011;63(8):2329-2339.

70. Plater-Zyberk C, Joosten LA, Helsen MM, Koenders MI, Baeuerle PA, van den Berg WB. Combined blockade of granulocyte-macrophage colony stimulating factor and interleukin 17 pathways potently suppresses chronic destructive arthritis in a tumour necrosis factor alpha-independent mouse model. Ann Rheum Dis. 2009;68(5):721-728.

71. van Nieuwenhuijze AE, van de Loo FA, Walgreen B, et al. Complementary action of granulocyte macrophage colony-stimulating factor and interleukin-17A induces interleukin-23, receptor activator of nuclear factor- $\kappa \mathrm{B}$ ligand, and matrix metalloproteinases and drives bone and cartilage pathology in experimental arthritis: rationale for combination therapy in rheumatoid arthritis. Arthritis Res Ther. 2015;17:163. 
72. Ruutu M, Thomas G, Steck R, et al. $\beta$-glucan triggers spondyloarthritis and Crohn's disease-like ileitis in SKG mice. Arthritis Rheum. 2012;64(7):2211-2222.

73. Benham H, Rehaume LM, Hasnain SZ, et al. Interleukin-23 mediates the intestinal response to microbial $\beta$-1,3-glucan and the development of spondyloarthritis pathology in SKG mice. Arthritis Rheumatol. 2014; 66(7):1755-1767.

74. Langley RG, Elewski BE, Lebwohl M, et al; ERASURE Study Group, FIXTURE Study Group. Secukinumab in plaque psoriasis - results of two phase 3 trials. $N$ Engl J Med. 2014;371(4):326-338.

75. Genovese MC, Durez P, Richards HB, et al. Efficacy and safety of secukinumab in patients with rheumatoid arthritis: a phase II, dose-finding, double-blind, randomised, placebo controlled study. Ann Rheum Dis. 2013;72(6):863-869.

76. Mease PJ, McInnes IB, Kirkham B, et al; FUTURE 1 Study Group Secukinumab inhibition of interleukin-17A in patients with psoriatic arthritis. $N$ Engl J Med. 2015;373(14):1329-1339.

77. McInnes IB, Mease PJ, Kirkham B, et al; FUTURE 2 Study Group. Secukinumab, a human anti-interleukin-17A monoclonal antibody, in patients with psoriatic arthritis (FUTURE 2): a randomised, double-blind, placebo-controlled, phase 3 trial. Lancet. 2015;386(9999):1137-1146.

78. Baeten DL, Braun J, Baraliakos X, et al. Secukinumab, a monoclonal antibody to interleukin-17A, significantly improves signs and symptoms of active ankylosing spondylitis: results of a 52-week phase 3 randomized placebo-controlled trial with intravenous loading and subcutaneous maintenance dosing. Arthritis Rheumatol. 2014;66(S10):S360.

79. Braun J, Deodhar AA, Sieper J, et al. Secukinumab significantly improves signs and symptoms of active ankylosing spondylitis: 52-week results from a randomized, double-blind, placebo-controlled phase 3 trial with subcutaneous loading and maintenance dosing [abstract]. Arthritis Rheumatol. 2015;67(suppl 10).

80. Burmester GR, Durez P, Shestakova G, et al. Association of HLA-DRB1 alleles with clinical responses to the anti-interleukin-17A monoclonal antibody secukinumab in active rheumatoid arthritis. Rheumatology (Oxford). 2016;55(1):49-55.

81. Lebwohl M, Strober B, Menter A, et al. Phase 3 studies comparing brodalumab with ustekinumab in psoriasis. N Engl J Med. 2015;373(14): 1318-1328.

82. Amgen. Amgen to Terminate Participation in Co-development and Commercialization of Brodalumab [press release]. Thousand Oaks, CA: PRNewswire; 2015 [May 22]. Available from: http://investors.amgen. com/phoenix.zhtml?c=61656\&p=irol-newsArticle $\&$ ID $=2052862$

83. Danesh MJ, Kimball AB. Brodalumab and suicidal ideation in the context of a recent economic crisis in the United States. J Am Acad Dermatol. 2016;74(1):190-192.

84. Hueber W, Patel DD, Dryja T, et al. Effects of AIN457, a fully human antibody to interleukin-17A, on psoriasis, rheumatoid arthritis, and uveitis. Sci Transl Med. 2010;2(52):52ra72.

85. Papp KA, Langley RG, Sigurgeirsson B, et al. Efficacy and safety of secukinumab in the treatment of moderate-to-severe plaque psoriasis: a randomized, double-blind, placebo-controlled phase II dose-ranging study. Br J Dermatol. 2013;168(2):412-421.

86. Blauvelt A, Prinz JC, Gottlieb AB, et al; FEATURE Study Group. Secukinumab administration by pre-filled syringe: efficacy, safety and usability results from a randomized controlled trial in psoriasis (FEATURE). Br J Dermatol. 2015;172(2):484- 493.

87. Genovese MC, Durez P, Richards HB, et al. One-year efficacy and safety results of secukinumab in patients with rheumatoid arthritis: phase II, dose-finding, double-blind, randomized, placebo-controlled study. J Rheumatol. 2014;41(3):414-421.

88. Koenders MI, Marijnissen RJ, Joosten LA, et al. T cell lessons from the rheumatoid arthritis synovium SCID mouse model: CD3-rich synovium lacks response to CTLA-4Ig but is successfully treated by interleukin-17 neutralization. Arthritis Rheum. 2012;64(6):1762-1770.
89. Novartis Pharmaceuticals. Efficacy at 24 Weeks and Safety, Tolerability and Long Term Efficacy up to 2 Years of Secukinumab (AIN457) in Patients With Active Rheumatoid Arthritis and an Inadequate Response to Anti-TNF $\alpha$ Agents (REASSURE). Available from: https://clinicaltrials.gov/ct2/show/NCT01377012

90. Novartis Pharmaceuticals. Safety and Efficacy of Extended Treatment With Secukinumab in Anti-TNF Inadequate Responders in RA (REASSURE-E). Available from: https://clinicaltrials.gov/ct2/show/ NCT01901900

91. McInnes IB, Sieper J, Braun J, et al. Efficacy and safety of secukinumab, a fully human anti-interleukin-17A monoclonal antibody, in patients with moderate-to-severe psoriatic arthritis: a 24-week, randomised, double-blind, placebo-controlled, phase II proof-of-concept trial. Ann Rheum Dis. 2014;73(2):349-356.

92. Novartis. Novartis receives two landmark European approvals for Cosentyx to treat patients with ankylosing spondylitis and psoriatic arthritis. Available from: https://www.novartis.com/news/ media-releases/novartis-receives-two-landmark-european-approvalscosentyx-treat-patients

93. Baeten D, Baraliakos X, Braun J, et al. Anti-interleukin-17A monoclonal antibody secukinumab in treatment of ankylosing spondylitis: a randomised, double-blind, placebo-controlled trial. Lancet. 2013;382(9906): 1705-1713.

94. Baraliakos X, Borah B, Braun J, et al. Long-term effects of secukinumab on MRI findings in relation to clinical efficacy in subjects with active ankylosing spondylitis: an observational study. Ann Rheum Dis. 2016; 75(2):408-412.

95. Baraliakos X, Deodhar AA, Braun J, et al. Effect of interleukin-17A inhibition on spinal radiographic changes through 2 years in patients with active ankylosing spondylitis: results of a phase 3 study with secukinumab [abstract]. Arthritis Rheumatol. 2015;67(suppl 10).

96. Baeten D, Sieper J, Braun J, et al; MEASURE 1 Study Group; MEASURE 2 Study Group. Secukinumab, an interleukin-17A Inhibitor, in ankylosing spondylitis. N Engl J Med. 2015;373(26):2534-2548.

97. Hueber W, Sands BE, Lewitzky S, et al; Secukinumab in Crohn's Disease Study Group. Secukinumab, a human anti-IL-17A monoclonal antibody, for moderate to severe Crohn's disease: unexpected results of a randomised, double-blind placebo-controlled trial. Gut. 2012;61(12): 1693-1700.

98. Targan SR, Feagan BG, Vermeire S, et al. A randomized, doubleblind, placebo-controlled study to evaluate the safety, tolerability, and efficacy of AMG 827 in subjects with moderate to severe Crohn's disease. Gastroenterology. 2012;143:E26.

99. O'Connor W Jr, Zenewicz LA, Flavell RA. The dual nature of $\mathrm{T}(\mathrm{H}) 17$ cells: shifting the focus to function. Nat Immunol. 2010;11(6): 471-476.

100. Dinarello CA, Simon A, van der Meer JW. Treating inflammation by blocking interleukin-1 in a broad spectrum of diseases. Nat Rev Drug Discov. 2012;11(8):633-652.

101. Braun J, van den Berg R, Baraliakos X, et al. 2010 update of the ASAS/EULAR recommendations for the management of ankylosing spondylitis. Ann Rheum Dis. 2011;70(6):896-904.

102. Smolen JS, Landewé R, Breedveld FC, et al. EULAR recommendations for the management of rheumatoid arthritis with synthetic and biological disease-modifying antirheumatic drugs: 2013 update. Ann Rheum Dis. 2014;73(3):492-509.

103. Smolen JS, Braun J, Dougados M, et al. Treating spondyloarthritis, including ankylosing spondylitis and psoriatic arthritis, to target: recommendations of an international task force. Ann Rheum Dis. 2014 73(1):6-16.

104. Gossec L, Smolen JS, Ramiro S, et al. European League Against Rheumatism (EULAR) recommendations for the management of psoriatic arthritis with pharmacological therapies: 2015 update. Ann Rheum Dis. 2016;75(3):499-510. 


\section{Publish your work in this journal}

Drug Design, Development and Therapy is an international, peerreviewed open-access journal that spans the spectrum of drug design and development through to clinical applications. Clinical outcomes, patient safety, and programs for the development and effective, safe, and sustained use of medicines are a feature of the journal, which

has also been accepted for indexing on PubMed Central. The manuscript management system is completely online and includes a very quick and fair peer-review system, which is all easy to use. Visit http://www.dovepress.com/testimonials.php to read real quotes from published authors.

Submit your manuscript here: http://www.dovepress.com/drug-design-development-and-therapy-journal 